\title{
BMJ Open Correlates of help-seeking by parents for the socioemotional development of their 3-year-old children: a longitudinal study
}

\author{
Jie Luo (D) , ${ }^{1}$ Hein Raat (D) , ${ }^{1}$ Carmen Betsy Franse, ${ }^{1}$ Rienke Bannink, ${ }^{2}$ \\ Guannan Bai (D) , ${ }^{1}$ Amy van Grieken (D) ${ }^{1}$
}

To cite: Luo J, Raat $\mathrm{H}$, Franse $\mathrm{CB}$, et al. Correlates of help-seeking by parents for the socioemotional development of their 3-year-old children: a longitudinal study. BMJ Open 2022;12:e052595. doi:10.1136/ bmjopen-2021-052595

- Prepublication history and additional supplemental material for this paper are available online. To view these files, please visit the journal online (http://dx.doi.org/10.1136/ bmjopen-2021-052595).

Received 20 April 2021 Accepted 07 December 2021

Check for updates

(c) Author(s) (or their employer(s)) 2022. Re-use permitted under CC BY-NC. No commercial re-use. See rights and permissions. Published by BMJ.

${ }^{1}$ Department of Public Health, Erasmus MC, University Medical Center Rotterdam, Rotterdam, The Netherlands

${ }^{2}$ CJG Rijnmond, Rotterdam, The Netherlands

Correspondence to

Dr Amy van Grieken;

a.vangrieken@erasmusmc.nl

\section{ABSTRACT}

Objectives Timely parental help-seeking regarding their child's socioemotional development is associated with a lower rate and lower severity of psychosocial problems in later life. This study aimed to examine the correlates of parental help-seeking for the socio-emotional development of 3-year-old children.

Design Retrospective cohort study.

Setting Community-based survey in Rotterdam.

Participants 0 2305 parents and their 2-year-old children at baseline, 1507 who completed follow-up questionnaires were included in the analyses when children were 3 years old.

Outcome measures Parental help-seeking regarding their child's socioemotional development and types of formal and informal help sources (eg, general practitioner, internet) used in the past 12 months were measured. Hierarchical logistic regression models were applied to identify factors correlates of parental help-seeking among 13 predisposing, enabling and need factors according to Andersen's behavioural model.

Results In total, $22.6 \%$ of parents reported help-seeking in the past 12 months for socioemotional development of their 3-year-old child; $6.8 \%$ addressed formal help sources and $17.5 \%$ addressed informal help sources. General practitioner (2.7\%) and family (12.5\%) were the most frequently used formal and informal sources, respectively. In the full model, predisposing factors associated with higher odds of parental help-seeking were child's other western ethnic background $(\mathrm{OR}=1.66,95 \% \mathrm{Cl} 1.02$ to 2.68) and parental age $\leq 29$ years old $(0 \mathrm{R}=1.71,95 \% \mathrm{Cl}$ 1.01 to 2.92). No associated factors were found among enabling factors. The need factors associated with higher odds of parental help-seeking were having previous helpseeking ( $\mathrm{OR}=2.52,95 \% \mathrm{Cl} 1.83$ to 3.48$)$ and discussing child's socioemotional development in the well-child visit $(\mathrm{OR}=2.47,95 \% \mathrm{Cl} 1.73$ to 3.53$)$.

Conclusions Predisposing and need factors were associated with parental help-seeking for socioemotional development of 3-year-old children. The findings can be used to further develop support for parents accessing adequate information, prevention and anticipatory care with regards to the child's socioemotional development.
Strengths and limitations of this study

- A longitudinal data set was realised from a diverse community population.

- A broad assessment of potential factors associated with parental help-seeking behaviour, including predisposing, enabling and need factors following Andersen's behavioural model, was performed.

- Both formal and informal types of help-seeking sources were studied.

- Self-reported help-seeking behaviour can be subjected to social desirability bias and recall bias.

- Generalisation is limited to the sample under study, the participation rate and loss to follow-up were considerable.

\section{INTRODUCTION}

Psychosocial problems, such as attention deficit hyperactivity disorders, conduct disorders and anxiety disorders, are relatively common among young children. ${ }^{12}$ The literature suggests that $7 \%-25 \%$ of children worldwide experience psychosocial problems in early childhood (0-6 years) ${ }^{3-8}$ Significantly, these psychosocial problems can track into adulthood. $^{9-11}$ Timely detection of (risk for) psychosocial problems and, consequently, offering appropriate interventions in early childhood can reduce problems and improve children's cognitive and academic performance. ${ }^{125}$

In order to identify psychosocial problems, validated instruments are often used for diagnosing emotional and behavioural problems in children under 18 years old. ${ }^{12}$ At younger ages, certain behaviours (eg, hitting, tantrums) can to some extent be part of the normal healthy development of psychosocial behaviour of a child. ${ }^{13}$ Therefore, for younger children instruments such as the Brief Infant-Toddler Social and Emotional Assessment (BITSEA) are used to 
detect 'at-risk' behaviour. Studies show that children's 'atrisk' behaviour can change to not at risk and vice versa over time. ${ }^{14}{ }^{15}$ Since young children's ability to express their psychosocial well-being is developing, parents and professionals have an important role in monitoring the child's socioemotional development. ${ }^{16-18}$ It is, therefore, important that parents take action for their concerns about their child's socioemotional development to determine whether and what type of support is needed.

Help-seeking for such concerns might be guided by several factors, and, in this regard, Andersen and Newman provide a framework for health service use. ${ }^{19}$ The framework postulates that the behaviour of health service use depends on the three core groups of factors: (1) predisposing factors (demographic and social characteristics), (2) enabling factors (the ability to access services) and (3) need factors (the internal and external need for healthcare services). Previous studies have found that predisposing factors, such as child's ethnic background and gender, are associated with parental help-seeking. ${ }^{20} 21$ Enabling factors, such as higher parental educational levels and higher incomes, have been shown to positively encourage parents to seek help for their child's problem behaviour (4-14 years old). ${ }^{22}$ An important need factor that has been reported to increase help-seeking by parents is recognition of the child's problem (6-11 years old). ${ }^{1724}$ Meanwhile, single-parent families, the high cost of professional mental health services and the self-stigma of parents have been indicated as barriers to help-seeking for children's socioemotional development (3-11 years old). ${ }^{25-27}$ It is estimated that approximately one-third of parents seek help for the socioemotional development of their children aged 4-11 who are at risk of psychosocial problems. ${ }^{25} 2829$ Moreover, thus far, research about parental help-seeking for the socioemotional development has focused on school-aged children (4-12 years old) and adolescents (12-18 years old) rather than preschool children (0-4 years old). ${ }^{21} 23242829$

In the literature so far, parental help-seeking for socioemotional problems of preschool children is rarely reported. Also, studies regarding parental help-seeking and children's socioemotional problems have often been evaluating on a limited number of potential correlates. ${ }^{30}$ The current study aimed to identify correlates of parental help-seeking regarding the socioemotional development of 3-year-old children. Following the Andersen and Newman framework, we studied the association between parental help-seeking and the three core factors: predisposing, enabling and need factors. In addition, we explored the formal and informal help sources used in help-seeking.

\section{METHODS}

\section{Study design and population}

For the present study, data were collected by parental questionnaires when the child was 2 years old and again with a follow-up at 3 years old. In 2014 and 2015, parents living

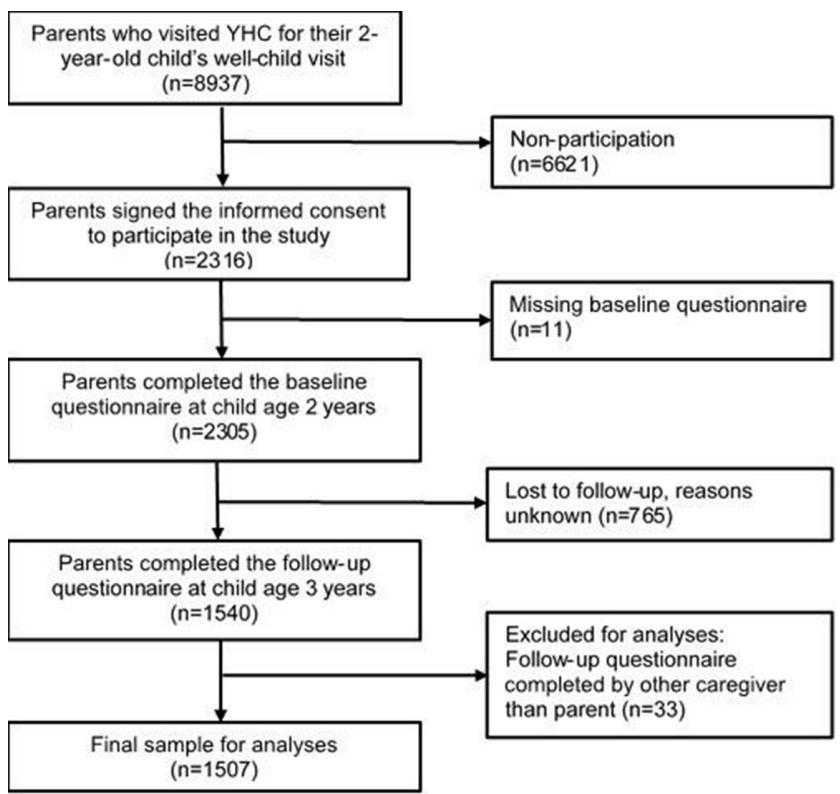

Figure 1 Population of analysis. YHC, Youth Health Care.

in the Rotterdam-Rijnmond area were invited by letter to participate in the study with their 2-year-old child. Parents were asked to complete and return the baseline questionnaire accompanied with a signed informed consent form when they visited the Dutch Preventive Youth Health Care (YHC) centre for their regular well-child visit. In the Netherlands, regular well-child visits are one element of YHC, which is offered free of charge to monitor and promote the health, well-being and development of children aged $0-19$ years. ${ }^{31}$ One year later, parents enrolled in the study received the follow-up questionnaire by e-mail or by mail with the request to return the completed questionnaire to the researchers in a pre-paid envelope.

From November 2014 to August 2015, 8937 parents attended for their 2-year child well-child visit, according to the YHC register. Of these, 2316 parents gave their consent to participate in the study (participation rate $=25.9 \%$ ) and 2305 parents completed the first questionnaires (response rate $=99.5 \%$ ). At the 1 -year follow-up, 1540 parents completed the second questionnaire. Children whose questionnaires were completed by other caregivers instead of their parents $(n=33)$ were excluded. Thus, 1507 participants were included in the analyses of this study (see figure 1).

\section{Parental help-seeking}

When the children were 3 years old, parental helpseeking was assessed by asking parents whether they had sought help in the past 12 months with regards to issues with their child's behaviour or socioemotional development. Parents could indicate yes/no whether they sought help at one or more of the following formal and informal help sources: (1) general practitioner (GP), (2) youth protection service, (3) mental healthcare professionals (eg, psychiatrist and child psychiatry outpatient clinic), (4) parenting support service (eg, parenting courses 
and pedagogue service), (5) social worker, (6) family, (7) friend/acquaintance/neighbour, (8) internet, (9) complementary medicine (eg, homoeopathy), (10) emergency telephone service, (11) prayer house (eg, church, mosque or synagogue). There was an open answer possibility for parents to report other sources, and answers were recoded into the existing response categories or recoded into the new generated options: (12) book/magazines, (13) daycare centre/school and (14) specialised medical care (eg, clinical, rehabilitation). Parents could choose multiple options. When the parent chose one of the above options, one point was scored. A total score was generated by summing up all confirmatory responses (range 0-14). Total scores were dichotomised into 'no' (none confirmatory options), indicating parents did not seek help from any sources and 'yes' (one or more confirmatory options), indicating parent sought help from one or more help sources for children's socioemotional development in the past 12 months.

\section{Formal and informal help sources}

The above response categories (1-14) were categorised into formal help sources and informal help sources. Formal help sources were GP (1), youth protection service (2), mental healthcare professionals (3), parenting support service (4), social worker (5) and specialised medical care (14). The remaining options were categorised as informal help: family (6), friend/acquaintance/ neighbour (7), internet (8), complementary medicine (9), emergency telephone service (10), prayer house (11), book/magazine (12) and daycare centre/school (13). Scores within each category were added up and two variables were generated: 'formal help source used' and 'informal help source used'. For both variables, the responses were dichotomised into 'no' (total score $=0$ ) and 'yes' (total score $\geq 1$ ).

\section{Potential correlates of parental help-seeking \\ Predisposing factors}

Predisposing factors included child age, child gender, child ethnic background and parental age measured at child-age-2 years. Child age (in months) at time of measurement was reported by parents. Child ethnic background (Dutch, other western, non-western) was defined based on country of birth of both parents according to the Classification of Statistics Netherlands. ${ }^{32}$ When both parents were born in the Netherlands, the child was considered to have a Dutch background. When one parent was born outside the Netherlands, this country of birth determined child's ethnic background. When both parents were born outside the Netherlands, mother's country of birth determined the child's ethnic background. ${ }^{32}$ Parental age (in years) was reported by parents at baseline and classified into three categories based on the distribution: ' $\geq 40$ years', ' $30-39$ years' and ' $\leq 29$ years'.

\section{Enabling factors}

Enabling factors assessed at 24 months included parental educational level, parental work status and family composition. Parental educational level was measured by one item asking about the highest level of education finalised by the respondent (mother or father) at 24 months. Educational level was categorised as high (higher vocational education, university), middle (higher secondary education, vocational education) or low (primary education, lower secondary education). ${ }^{33}$ Respondents to the questionnaire were asked to report their work status. Parental work status reflects in $89.3 \%$ the mother's employment and $10.7 \%$ the father's work status. Parental work status was classified as 'employed (including full-time job and part-time job)' and 'unemployed'. The family composition was categorised into two-parent family or one-parent family.

\section{Need factors}

Need factors included the BITSEA Problem and Competence scale, stressful life events, child's general health, parental satisfaction of child's development, previous help-seeking and discussing child's socioemotional development in the well-child visit.

The BITSEA consists of a 31-item Problem scale and an 11-item Competence scale, which measures psychosocial well-being in children 12-36 months. Each item is scored 0 for 'not true', 1 for 'somewhat true' and 2 for 'certainly true'. ${ }^{34}$ The items from the two scales of BITSEA are summed up independently. A score of 14 or higher on the Problem scale was categorised as 'at risk of psychosocial problems', and a score of 15 or lower on the competence scale was termed as 'at risk of competence delay'. ${ }^{35}$ In the previous study of Kruizinga among Dutch parents and children $(n=3127)$, the BITSEA showed Cronbach's alphas of 0.76 and 0.63 , and a test-retest reliability of 0.75 and $0.61 .{ }^{37}$ In the present study, the Cronbach's alphas were 0.74 and 0.54 .

Stressful life events were measured by assessing the occurrence of 12 stressful life events, such as a family relocation, divorce or financial problems. If an event had happened, parents indicated when the specific life event happened: last year, 1-2 years ago, 3-4 years ago or more than 4 years ago. When parents confirmed the occurrence of one event within the past 2 years (the first two options), one point was scored. If one event happened 2 years ago, then the event was not counted as a stressful life event for the child. A total score was calculated by summing up the points assigned. The stressful life event variable was generated with two categories based on the total score: total score 0 indicating 'no' and $\geq 1$ 'yes'.

The child's general health (good vs poor) and parental satisfaction of the child's development (yes vs no) were measured by two subscales of the Infant Toddler Quality of Life Questionnaire of 47 items (ITQOL-SF47). ${ }^{38}$ According to the user manual, the raw scores of each variable were transformed and dichotomised. The scores above the cut-off point indicated a child's good general 
health and parent-satisfied development, respectively. ${ }^{39}$ In previous research by Raat among general Dutch children $(n=500)$, these two subscales showed Cronbach's alphas of 0.76 and 0.63 , and a test-retest reliability of 0.75 and $0.6{ }^{40}$ The Cronbach's alphas of the general health and parent-satisfied development in this study were 0.59 and 0.67 .

Previous help-seeking was assessed at 24 months with the question: 'Have you sought help for your child due to his/her socioemotional development from the following sources in the past twoyears?'. The answer options (1-14) were the same as the help-seeking question at 36 months. These options were recategorised in the same way: 'no' (none confirmatory options) and 'yes' (one or more confirmatory options).

The discussion of the child's socioemotional development in the well-child visit was measured by one question: 'During the regular well-child visit with YHC when the child was two years old, were any specifics regarding your child's behaviour, social, and emotional development discussed?' The options were 'no' and 'yes'.

\section{Patient and public involvement statement}

Neither patients nor the public was involved in the planning, design, conduct or reporting of this study.

\section{Statistical analysis}

Descriptive statistics were used to describe the characteristics of the study population. Hierarchical logistic regression models were fitted to investigate the correlates of help-seeking. Data were collected during the well-child visit when child was 2 years old, so the age of child was removed from the logistic regression analysis. All categorised variables were included as the independent variables by block. The Omnibus Test, a likelihood ratio $\chi^{2}$ statistic, was used to assess the contribution of each block of variables to the model. ${ }^{41}$ The first model (model 1) regarded predisposing variables as independent variables. The second model (model 2) additionally included enabling variables as independent variables. Finally, a third full model (model 3) with all variables from the three blocks was fitted. Descriptive statistics were used to describe formal and informal help-seeking of parents. Multicollinearity was examined using correlation analyses for categorical variables. Maximal coefficient $r=0.254$ indicated a weak correlation $(0.2<\mathrm{r}<0.4)$; therefore, all variables were included in the regression analyses.

Furthermore, we assessed interactions between the 13 potential correlates of help-seeking behaviour and child gender, child ethnic background, parental age and parental education level with regards to the association with help-seeking. After applying Bonferroni correction for multiple testing $(\mathrm{p}=0.05 / 42=0.001)$, no statistically significant interactions were found (online supplemental table S1). A non-response analysis was conducted to assess differences between participants participating in follow-up and those lost to follow-up (online supplemental table S2). The McNemar's test was applied to examine whether more parents used informal help sources among the parents who reported help-seeking (online supplemental table S3). To provide more details, the characteristics of the study population by use of sources were provided in the online supplemental table S4.

Regarding the missing data among the sample of 1507 children, multiple imputation by fully conditional specification was used to deal with the missing values on all independent variables in SPSS version $25 .^{42}$ The pooled results of five imputed data sets were used. Finally, we performed a sensitivity analysis using complete-case data without missing values to check the robustness of results (online supplemental table S5). A p value $<0.05$ was considered to be statistically significant. All analyses were completed using the IBM SPSS V.25 (IBM, Armonk, New York).

\section{RESULTS}

\section{Characteristics of the study population}

Of all parents, 22.6\% ( $\mathrm{n}=341)$ reported help-seeking in the past 12 months for their 3-year-old child's psychosocial health; $6.8 \%(\mathrm{n}=103)$ addressed formal help sources and $17.5 \%(\mathrm{n}=264)$ addressed informal help sources. As for children, the mean age was $24.5(\mathrm{SD}=1.8)$ months (table 1). Half of the children were boys (49.4\%), 80.2\% were Dutch and $93.8 \%$ of the children lived in a twoparent family. Most parents were $30-39$ years old $(70.1 \%)$, employed $(81.8 \%)$ and $59.9 \%$ had a high educational level.

Regarding comparison between parents with helpseeking experience and their counterparts, two predisposing factors, child age $(p>0.05)$ and child gender ( $>0.05$ ), were not significantly different.

\section{Correlates of parental help-seeking}

Table 2 presents the results of logistic regression analyses. Model 1 with predisposing factors as independent factors showed that having an other-western ethnic background $(\mathrm{OR}=1.73,95 \% \mathrm{CI} 1.10$ to 2.71$)$ and non-western ethnic background as a child (OR=1.51, 95\% CI 1.05 to 2.18$)$ as well as parental age $\leq 29$ years old $(\mathrm{OR}=2.28,95 \%$ CI 1.38 to 3.77) were associated with higher odds of parental help-seeking.

Model 2 shows the association between predisposing factors and enabling factors. Of predisposing factors, having an other-western ethnic background $(\mathrm{OR}=1.66$, $95 \% \mathrm{CI} 1.05$ to 2.60$)$ and parental age $\leq 29$ years old $(\mathrm{OR}=1.96,95 \% \mathrm{CI} 1.17$ to 3.27$)$ were associated with parental help-seeking. Two enabling factors, parental educational level $(\mathrm{OR}=1.36,95 \%$ CI 1.04 to 1.79$)$ and parental employed status (OR=1.47, 95\% CI 1.07 to 2.02), were associated with higher odds of parental help-seeking.

In the full model (model 3), two predisposing factors having an other-western ethnic background as a child $(\mathrm{OR}=1.66,95 \% \mathrm{CI} 1.02$ to 2.68$)$ and parental age $\leq 29$ years old (OR=1.71, 95\% CI 1.01 to 2.92$)$ were associated with higher odds for parental help-seeking. No associations were found between enabling factors and 
Table 1 Characteristics of the study population $(n=1507)$

\begin{tabular}{|c|c|c|c|c|}
\hline \multirow[b]{2}{*}{ Items } & \multirow{2}{*}{$\begin{array}{l}\text { Total } \\
(\mathrm{n}=1507) \\
\text { Mean } \pm \text { SD n (\%) }\end{array}$} & \multicolumn{2}{|l|}{ Help-seeking } & \multirow[b]{2}{*}{$P$ value } \\
\hline & & $\begin{array}{l}\text { No }(n=1166) \\
\text { Mean } \pm \text { SDn }(\%)\end{array}$ & $\begin{array}{l}\text { Yes }(n=341) \\
\text { Mean } \pm \text { SD } n(\%)\end{array}$ & \\
\hline Child age in months & $24.5 \pm 1.8$ & $24.5 \pm 1.8$ & $24.5 \pm 1.9$ & 0.802 \\
\hline Child gender & & & & 0.566 \\
\hline Child ethnic backgroun & & & & $0.026^{\star}$ \\
\hline Dutch & $1161(80.2)$ & $917(81.7)$ & $244(75.1)$ & \\
\hline Other western & $107(7.4)$ & $75(6.7)$ & $32(9.8)$ & \\
\hline Non-western & $179(12.4)$ & $130(11.6)$ & $49(15.1)$ & \\
\hline$\leq 29$ & $282(18.9)$ & $200(17.3)$ & $82(24.3)$ & \\
\hline \multicolumn{5}{|l|}{ Enabling factors } \\
\hline Parental educational le & & & & $0.003^{\star \star}$ \\
\hline High & $883(59.9)$ & $710(62.3)$ & $173(52.0)$ & \\
\hline Middle & $498(33.8)$ & $362(31.8)$ & $136(40.8)$ & \\
\hline Low & $92(6.2)$ & $68(6.0)$ & $24(7.2)$ & \\
\hline Parental work status & & & & $<0.001^{\star \star \star}$ \\
\hline Employed & 1195 (81.8) & 947 (83.9) & $248(74.7)$ & \\
\hline No risk & $1400(94.0)$ & 1101 (95.6) & $299(88.5)$ & \\
\hline At risk & $90(6.0)$ & $51(4.4)$ & 39 (11.5) & \\
\hline \multicolumn{2}{|c|}{ BITSEA Competence scale score } & & & $0.011^{*}$ \\
\hline No risk & $1300(88.0)$ & $1017(89.1)$ & $283(84.0)$ & \\
\hline At risk & $178(12.0)$ & $124(10.9)$ & $54(16.0)$ & \\
\hline Stressful life events & & & & $<0.001^{\star \star \star}$ \\
\hline No & $749(51.0)$ & $608(53.5)$ & $141(42.3)$ & \\
\hline Yes & $720(49.0)$ & $528(46.5)$ & $192(57.7)$ & \\
\hline \multicolumn{2}{|c|}{ General health of the child* } & & & $0.007^{\star *}$ \\
\hline Good & 1370 (92.2) & 1070 (93.2) & $300(88.8)$ & \\
\hline Poor & $116(7.8)$ & $78(6.8)$ & $38(11.2)$ & \\
\hline \multicolumn{2}{|c|}{ Parental satisfaction of child's development† } & & & $<0.001^{\star \star \star}$ \\
\hline Yes & $1380(94.7)$ & $1074(95.9)$ & $306(90.5)$ & \\
\hline No & $78(5.3)$ & $46(4.1)$ & $32(9.5)$ & \\
\hline \multicolumn{2}{|l|}{ Previous help-seeking } & & & $<0.001^{\star \star \star}$ \\
\hline No & 1208 (82.2) & $992(87.1)$ & $216(65.5)$ & \\
\hline Yes & $261(17.8)$ & $147(12.9)$ & $114(34.5)$ & \\
\hline
\end{tabular}




\begin{tabular}{|c|c|c|c|c|}
\hline \multirow[b]{2}{*}{ Items } & \multirow{2}{*}{$\begin{array}{l}\text { Total } \\
(n=1507) \\
\text { Mean+SDn (\%) }\end{array}$} & \multicolumn{2}{|l|}{ Help-seeking } & \multirow[b]{2}{*}{$P$ value } \\
\hline & & $\begin{array}{l}\text { No }(n=1166) \\
\text { Mean } \pm \text { SD } n(\%)\end{array}$ & $\begin{array}{l}\text { Yes }(n=341) \\
\text { Mean } \pm S D n(\%)\end{array}$ & \\
\hline No & 1196 (85.6) & 980 (89.8) & 216 (70.6) & \\
\hline Yes & 201 (14.4) & $111(10.2)$ & $90(29.4)$ & \\
\hline
\end{tabular}

This table presents non-imputed data.

The missing numbers of variables are child gender $(n=10)$, child ethnic background $(n=60)$, parental age $(n=11)$, parental educational level $(n=34)$, parental work status $(n=46)$, family composition $(n=29)$, BITSEA Problem scale score $(n=17)$, BITSEA Competence scale score $(n=29)$, stressful life events $(n=38)$, general health of the child $(n=21)$, parental satisfaction of child's development $(n=49)$, previous help-seeking $(n=38)$ and discussion of child socio-emotional development in the well-child visit $(n=110)$.

Data presented as mean \pm SD or number (percentage). Significant differences between two subgroups of help-seeking and non-help-seeking parents were evaluated at 0.05 level using independent $T$ tests for continuous variables and $\chi^{2}$ tests for categorical variables.

${ }^{*} \mathrm{p}<0.05 ;{ }^{* \star} \mathrm{p}<0.01 ;{ }^{* \star *} \mathrm{p}<0.001$.

*General health of the child was measured by the 4-item subscale General Health of the Infant Toddler Quality of Life Questionnaire (47 items). †Parental satisfaction of child's development was measured by the 5-item subscale Satisfaction of Child's Development of the Infant Toddler Quality of Life Questionnaire (47 items).

BITSEA, Brief Infant-Toddler Social and Emotional Assessment.

parental help-seeking. Of the need factors, previous helpseeking ( $\mathrm{OR}=2.52,95 \%$ CI 1.83 to 3.48 ) and discussion of child socioemotional development in the well-child visit $(\mathrm{OR}=2.47,95 \% \mathrm{CI} 1.73$ to 3.53$)$ were associated with higher odds of parental help-seeking for socioemotional development at child age 3 years. The block of need factors contributed most to the full model according to the $\chi^{2}$ by the Omnibus Test (all $\mathrm{p}$ values $<0.05$ ).

\section{Use of formal and informal help sources}

Table 3 shows the frequency of formal and informal help sources used in parental help-seeking for their 3-year-old child's socioemotional development in the past 12 months. Among the 341 parents who reported help-seeking, fewer parents $(n=103)$ reported the use of formal help sources than parents $(n=264)$ who reported the use of informal help sources $(\mathrm{p}<0.001$, online supplemental table $\mathrm{S} 3)$; only $26(7.6 \%)$ parents used both formal and informal help sources. The GP (12.0\%) and parenting support services, such as parenting courses $(9.4 \%)$, were the most frequently used formal help sources. Family $(55.4 \%)$ and friends/acquaintance/neighbour $(40.5 \%)$ were the most frequently used informal help sources. Characteristics of the study population by use of sources in parental helpseeking are presented in online supplemental table S4.

\section{Additional data analyses}

Compared with participants lost in the follow-up ( $\mathrm{n}=775)$, participants in the follow-up ( $\mathrm{n}=1540)$ were, as a child, more likely to be at a younger age and have a Dutch ethnic background and, as a parent, to be at an older age and have a higher educational level (all $\mathrm{p}<0.001$ ). No significant differences were found between boys and girls ( $p>0.05)$ (online supplemental table S2).

Online supplemental table S5 shows the results of multivariate logistic regression conducted with non-imputed complete data. There was a difference between the full models of multivariate logistic regression conducted with non-imputed data and those with imputed data. In the imputed data analysis, parents of a child with otherwestern ethnic background ( $\mathrm{OR}=1.66,95 \% \mathrm{CI} 1.02$ to 2.68) in the predisposing block were more likely to have help-seeking. This association was not significant $(\mathrm{OR}=1.51,95 \%$ CI 0.87 to 2.63$)$ in the analysis conducted with complete data. On the other hand, stressful life events $(\mathrm{OR}=1.45,95 \%$ CI 1.07 to 1.96$)$ in the need block were associated with help-seeking in the complete data analysis but not in the imputed data analysis $(\mathrm{OR}=1.29$, $95 \%$ CI 0.98 to 1.68$)$. Although the significance of the two factors changed, the pattern of relevant factors was similar. The rest of the factors in three blocks kept the same association and significance in the imputed data analysis and the complete data analysis, thereby indicating the robustness of the model. Furthermore, we conducted the $\chi^{2}$ test of homogeneity, which showed that there were no significant differences (all $p$ values $>0.05$ ) between the characteristics of the imputed data and the complete data (online supplemental table S6).

\section{DISCUSSION}

In the present study, correlates of parental help-seeking for the socioemotional development of 3-year-old children were studied. Among predisposing factors, having an other-western ethnic background as a child and parental age younger than 29 years old indicated higher odds of parental help-seeking for the socioemotional development of children aged 3 years. Also, previous help-seeking and discussing the child's socioemotional development in the well-child visit as need factors were associated with higher odds for parental help-seeking. No correlate of parental help-seeking was found among enabling factors. 
Table 2 Associations between predisposing, enabling and need factors and parental help-seeking in the past 12 months for the 3-year-old child ( $n=1507)$

\begin{tabular}{|c|c|c|c|c|c|c|}
\hline & \multicolumn{4}{|l|}{ Multivariate } & & \\
\hline & \multicolumn{2}{|l|}{ Model 1} & \multicolumn{2}{|c|}{ Model 2} & \multicolumn{2}{|c|}{ Model 3} \\
\hline & \multicolumn{2}{|l|}{$\begin{array}{l}\text { Predisposing } \\
\text { variables }\end{array}$} & \multicolumn{2}{|c|}{ Plus enabling variables } & \multicolumn{2}{|c|}{ Plus need variables } \\
\hline & \multicolumn{2}{|l|}{$\chi^{2}=22.38$} & \multicolumn{2}{|c|}{$\chi^{2}=16.79$} & \multicolumn{2}{|c|}{$\chi^{2}=107.09$} \\
\hline Block statistics & OR & $95 \% \mathrm{Cl}$ & OR & $95 \% \mathrm{Cl}$ & OR & $95 \% \mathrm{Cl}$ \\
\hline \multicolumn{7}{|l|}{ Predisposing factors } \\
\hline \multicolumn{7}{|l|}{ Child gender } \\
\hline Boys & Ref & & Ref & & Ref & \\
\hline Girls & 0.93 & 0.73 to 1.19 & 0.93 & 0.73 to 1.19 & 0.98 & 0.75 to 1.27 \\
\hline \multicolumn{7}{|l|}{$\begin{array}{l}\text { Child ethnic } \\
\text { background }\end{array}$} \\
\hline Dutch & Ref & & Ref & & Ref & \\
\hline Other western & $1.73^{*}$ & 1.10 to 2.71 & $1.66^{*}$ & 1.05 to 2.60 & $1.66^{*}$ & 1.02 to 2.68 \\
\hline Non-western & $1.51^{*}$ & 1.05 to 2.18 & 1.20 & 0.81 to 1.78 & 1.18 & 0.77 to 1.79 \\
\hline \multicolumn{7}{|l|}{ Parental age in year } \\
\hline$\geq 40$ & Ref & & Ref & & Ref & \\
\hline 30-39 & 1.56 & 0.99 to 2.46 & 1.57 & 1.00 to 2.46 & 1.45 & 0.90 to 2.32 \\
\hline$\leq 29$ & $2.28^{\star \star}$ & 1.38 to 3.77 & $1.96^{*}$ & 1.17 to 3.27 & $1.71^{*}$ & 1.01 to 2.92 \\
\hline \multicolumn{7}{|l|}{ Enabling factors } \\
\hline \multicolumn{7}{|l|}{$\begin{array}{l}\text { Parental } \\
\text { educational level }\end{array}$} \\
\hline High & & & Ref & & Ref & \\
\hline Middle & & & $1.36^{*}$ & 1.04 to 1.79 & 1.30 & 0.97 to 1.74 \\
\hline Low & & & 1.12 & 0.67 to 1.89 & 1.10 & 0.63 to 1.90 \\
\hline \multicolumn{7}{|l|}{$\begin{array}{l}\text { Parental work } \\
\text { status }\end{array}$} \\
\hline Employed & & & Ref & & Ref & \\
\hline Unemployed & & & $1.47^{*}$ & 1.07 to 2.02 & 1.28 & 0.91 to 1.80 \\
\hline \multicolumn{7}{|l|}{ Family composition } \\
\hline Two-parent family & & & Ref & & Ref & \\
\hline $\begin{array}{l}\text { Single-parent } \\
\text { family }\end{array}$ & & & 1.51 & 0.95 to 2.41 & 1.31 & 0.80 to 2.15 \\
\hline \multicolumn{7}{|l|}{ Need factors } \\
\hline \multicolumn{7}{|l|}{$\begin{array}{l}\text { BITSEA Problem } \\
\text { scale score }\end{array}$} \\
\hline No risk & & & & & Ref & \\
\hline At risk & & & & & 1.20 & 0.72 to 1.99 \\
\hline \multicolumn{7}{|l|}{$\begin{array}{l}\text { BITSEA } \\
\text { Competence scale } \\
\text { score }\end{array}$} \\
\hline No risk & & & & & Ref & \\
\hline At risk & & & & & 1.18 & 0.78 to 1.79 \\
\hline \multicolumn{7}{|l|}{ Stressful life events } \\
\hline No & & & & & Ref & \\
\hline Yes & & & & & 1.29 & 0.98 to 1.68 \\
\hline
\end{tabular}


Table 2 Continued

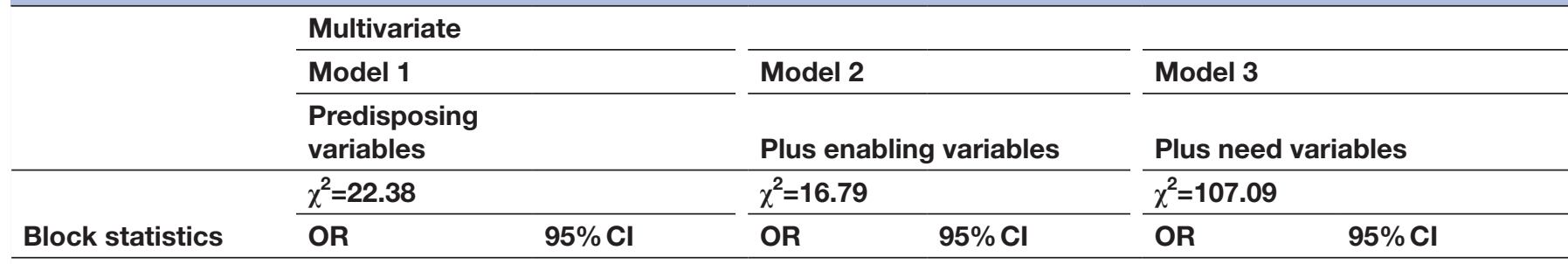

General health of

the child*

\begin{tabular}{|c|c|c|}
\hline Good & Ref & \\
\hline Poor & 1.16 & 0.73 to 1.85 \\
\hline \multicolumn{3}{|c|}{$\begin{array}{l}\text { Parental satisfaction } \\
\text { of child's } \\
\text { development } †\end{array}$} \\
\hline Yes & Ref & \\
\hline No & Ref & \\
\hline Yes & $2.52^{\star \star \star}$ & 1.83 to 3.48 \\
\hline \multicolumn{3}{|c|}{$\begin{array}{l}\text { Discussion of child } \\
\text { socio-emotional } \\
\text { development in the } \\
\text { well-child visit }\end{array}$} \\
\hline Yes & $2.47^{\star \star \star}$ & 1.73 to 3.53 \\
\hline
\end{tabular}

Model 1: The model with predisposing factors as independent variables.

Model 2: The model with predisposing and enabling factors as independent variables.

Model 3: The full model with predisposing, enabling, and need factors as independent variables.

${ }^{*} p<0.05 ;{ }^{* \star} p<0.01 ;{ }^{* \star *} p<0.001$.

${ }^{*}$ General health of the child was measured by the 4-item subscale General Health of the Infant Toddler Quality of Life Questionnaire (47 items).

†Parental satisfaction of child's development was measured by the 5-item subscale Satisfaction of Child's Development of the Infant Toddler Quality of Life Questionnaire (47 items).

BITSEA, Brief Infant-Toddler Social and Emotional Assessment; $\chi^{2}$, model chi-square for each block of variables, all significant at $p<0.05$.

In the present study predisposing, enabling and need factors were evaluated in relation to help-seeking behaviour. The Andersen and Newman's framework composes of environment, population characteristics, health behaviour and outcome related to help-seeking behaviour. $^{43}$ In the current study, the information on the environment (including the healthcare system and external environment) and the information on the outcome (including perceived health status, evaluated health status, and consumer satisfaction) were not collected. We recommend future studies to get a complete overview of factors associated with help-seeking behaviour. The findings of predisposing factors indicated that parents of child with other-western background were more likely to seek help, compared with parents of Dutch children. Existing studies on the association between minority ethnic background and help-seeking for children's socioemotional development have shown conflicting results. ${ }^{44-47}$ These differing results may be due to the different characteristics of minor ethnic backgrounds as well as differing help-seeking measures among the studies. ${ }^{47}$ Although parents of children from minority ethnic background perceived more barriers to access formal help-seeking, studies report that these parents are able to access informal help sources as easily and as equally to native parents. ${ }^{26} 49-51$ Moreover, the healthcare framework in the Netherlands (eg, equal primary care, collaboration of professionals in the community, universal healthcare) and social contexture (eg, language and cultural similarity) may partly reduce barriers to healthcare among the parents with other-western background. ${ }^{52-54}$ Besides the child's otherwestern background, as a predisposing factor, parental age was also associated with help-seeking: younger parents 
Table 3 Use of formal and informal help sources in parental help-seeking in the past 12 months for the 3-year-old child $(n=1507)$

\begin{tabular}{lccc}
\hline & & \multicolumn{1}{c}{ Total } \\
sample \\
& $\mathbf{n}$ & $\begin{array}{l}\text { (\%) } \\
\text { Help-seeking } \\
\text { (yes) (\%) }\end{array}$ \\
\hline $\begin{array}{l}\text { Parents reported } \\
\text { use of help sources } \\
\text { (yes) }\end{array}$ & 341 & 22.6 & 100.0 \\
$\begin{array}{l}\text { Formal and } \\
\text { informal help }\end{array}$ & 26 & 1.7 & 7.6 \\
$\begin{array}{l}\text { sources } \\
\text { Formal help } \\
\text { source(s) only }\end{array}$ & 77 & 5.1 & \\
\hline $\begin{array}{l}\text { Informal help } \\
\text { source(s) only }\end{array}$ & 238 & 15.8 & 69.8 \\
\hline
\end{tabular}

Type of help

sources

\begin{tabular}{|c|c|c|c|}
\hline Formal sources (yes) & 103 & 6.8 & 30.2 \\
\hline $\begin{array}{l}\text { General } \\
\text { practitioner }\end{array}$ & 41 & 2.7 & 12.0 \\
\hline $\begin{array}{l}\text { Parenting support } \\
\text { service }\end{array}$ & 32 & 2.1 & 9.4 \\
\hline $\begin{array}{l}\text { Specialised } \\
\text { medical care }\end{array}$ & 20 & 1.3 & 5.9 \\
\hline $\begin{array}{l}\text { Youth protection } \\
\text { services }\end{array}$ & 18 & 1.2 & 5.3 \\
\hline $\begin{array}{l}\text { Mental healthcare } \\
\text { professionals }\end{array}$ & 11 & 0.7 & 3.2 \\
\hline Social worker & 1 & 0.1 & 0.3 \\
\hline $\begin{array}{l}\text { Informal sources } \\
\text { (yes) }\end{array}$ & 264 & 17.5 & 77.4 \\
\hline Family & 189 & 12.5 & 55.4 \\
\hline $\begin{array}{l}\text { Friend/ } \\
\text { acquaintance/ } \\
\text { neighbour }\end{array}$ & 138 & 9.2 & 40.5 \\
\hline Internet & 71 & 4.7 & 20.8 \\
\hline $\begin{array}{l}\text { Daycare centre/ } \\
\text { school }\end{array}$ & 12 & 0.8 & 3.5 \\
\hline $\begin{array}{l}\text { Complementary } \\
\text { medicine }\end{array}$ & 4 & 0.3 & 1.2 \\
\hline $\begin{array}{l}\text { Emergency } \\
\text { telephone service }\end{array}$ & 3 & 0.2 & 0.9 \\
\hline Book/magazine & 2 & 0.1 & 0.6 \\
\hline Prayer house & 1 & 0.1 & 0.3 \\
\hline
\end{tabular}

Parents could endorse more than one option; hence, the sum of each subcategory does not total up to $100 \%$.

were more likely to seek help for their 3-year-old child. Previous studies have reported first-time parents to be more open and actively involved in searching for information about parenting and child development. ${ }^{55}$ First-time parents are also more likely to reach out for help. ${ }^{56}$ In the current study, we were unable to adapt for the parity of the child; therefore, we were not able to evaluate whether this explanation might hold for our findings.

With regards to enabling factors without correction for the need factors, parental educational level and employment status were associated with help-seeking. After correction for the need factors, parental educational level, employment status and family composition were not significantly associated. Studies on association between three enabling factors and help-seeking have reported contrary results. In the Netherlands, equal access to primary care (eg, GPs and YHC), to comprehensive care professionals in clinics and communities, and to universal healthcare may reduce the barriers for parents in the enabling domain. ${ }^{52}{ }^{53}$ Similar results have been found in other studies conducted in a similar context. ${ }^{515758}$

The need factors in the Andersen and Newman's framework consist of perceived need and evaluated need. ${ }^{43}$ Parent-reported general health of the child and parental satisfaction with child's development reflect most closely the perceived need, while the BITSEA score and discussion with YHC professionals most closely reflect the evaluated need (ie, being more clinical assessments). With regards to need factors, we observed that parents seeking any help for their child's socioemotional development before the age of 2 years were more likely to seek help in the past 12 months at child age 3 years. It is plausible that parents who had previous help-seeking may be able to deal better with barriers (eg, parents' self-stigma) and with exploring more sources in terms of help-seeking. ${ }^{47}$ In addition, the literature regarding the use of mental health service for children and adolescents suggests that social and emotional problems exist over a longer period of time. ${ }^{21}{ }^{59}$ Therefore, it is suggested that for actual problem behaviour longitudinal care is needed. ${ }^{11} 2960$ Furthermore, parents who had previously discussed their child's socioemotional development in the well-child visit at the child age of 2 years were more likely to seek help in the past 12 months. In the Netherlands, the discussion during the well-child visit could be raised by parents or YHC professionals. The YHC professionals can suggest a discussion based on the evaluation of the child's socioemotional development. Parents also can consult on this issue if they are concerned about their child's socioemotional development. In this capacity, the YHC professional assists the parent in recognising early childhood psychosocial problems. Although recognition of problem behaviour by parents has been reported to be difficult for parents, it is important for them to be able to seek help in time. ${ }^{5} 17202844$ The YHC, thus plays a crucial role in screening and identifying children's social and emotional problems in the Netherlands. ${ }^{61}$

In total, $6.0 \%$ of 1507 children were at risk of socioemotional problems measured by BITSEA Problem scale, and $12 \%$ were at risk of delay of socioemotional competence measured by BITSEA Competence scale. The rates of socioemotional development problems in this study were comparable with these measured by other instruments, 
such as $17 \%$ at moderate risk and $11 \%$ at high risk of developmental delays measured by the Parent Evaluation of Developmental Status among children ( $0-5$ years old) in the American National Survey of Children's Health. ${ }^{62}$ Consistent with previous studies on school-aged children, our results showed that formal help sources were used less frequently than informal help sources for children's socioemotional development. ${ }^{24}{ }^{25}$ Gaining access to formal help sources may have more barriers, such as iterative referral processes, long waiting times and high costs. ${ }^{26} 4963$ The informal help sources most often used in this study were the parental social network as well as information from books and the internet. ${ }^{5064}$ Accordingly, compared with formal help sources, informal help sources might be more directly available and accessible for parents when they are seeking help for their children's socioemotional development. ${ }^{6365}$

Timely parental help-seeking for the socioemotional development of children is associated with a lower rate and lower severity of psychosocial problems in later life. ${ }^{125}$ This study provides insight into parental helpseeking when their children are very young. The findings indicated that parents of preschool children, for example, most frequently used help sources close by, such as family, while books and magazines were less frequently used. In addition, investments might be made towards improving parents' access to formal healthcare use for their children (eg, provide the access to online consultation given by psychological professionals). Previous research has suggested, especially among non-native parents, limited and difficult access to healthcare facilities. ${ }^{206}$ Longitudinal and experimental studies are recommended to examine the differential pathways between parentperceived versus diagnosed child psychosocial problems and the use of healthcare. Environment factors, including health care system and external environment, should be studied as contemplated by the Andersen model; taking into account access parents have to healthcare, but also barriers they perceive to make use of healthcare. Qualitative and quantitative methods should be combined. Regarding the BITSEA and subscales of the ITQOL-SF47 in this study, some coefficients of reliability were lower than the suggested guideline of 0.70 , especially the interrater reliability correlations (0.3 and 0.17) of BITSEA. However, these reported low correlations were the correlations between parents and daycare teachers, which are typically lower than the correlations between parents. ${ }^{67}$ We recommend future studies to evaluate the reliability and repeated assessments especially in diverse samples to check the robustness of our findings.

The present study has several strengths. First, the longitudinal correlates between predisposing, enabling and need factors and parental help-seeking were studied among a large community sample of parents of 3-year-old children. Parental help-seeking for children under 4 years old is rarely studied. ${ }^{24} 2548$ Second, formal and informal help sources in parental help-seeking were included. Specifically, a broad range of informal help sources, for example, internet, books, complementary medicine and religious institutes were assessed. Nevertheless, there were some limitations that need to be addressed. First, helpseeking for perceived social and emotional problems was parent reported. Parents may have underestimated or overestimated their child's socioemotional development. The assessment focussed on parents' perceived socioemotional problems contrary to a clinical diagnosis. In our analyses, we did correct for risk of psychosocial problems at age 2 years, assessed by the BITSEA. A combination of clinical diagnose instruments, such as the Child Behavior Checklist, with parent perceived problems, may contribute to a better understanding of parental help-seeking behaviour. ${ }^{68}$ Second, information on the help-seeking is self-reported and recall bias is possible; however, the 1-year recall might have decreased recall inaccuracy. ${ }^{69}$ Third, the multivariate regression analyses showed a slight difference between results conducted with the complete data and those with the imputed data. Therefore, we assessed the homogeneity of the above two data sets (online supplemental table S6) and found no significant difference in the characteristics of the two populations $(p>0.05)$. Fourth, a limitation is the participation rate and the loss to follow-up in the present study. The participation rate was $25.9 \%$, which is lower than reported participation rates in large birth cohorts (around $30 \%-40 \%) .{ }^{70}$ We were not able to receive information from parents themselves as to why they refused to participate. Common reasons for non-participation are a lack of interest or a lack of time. ${ }^{71}{ }^{72}$ In addition, we cannot ascertain that all parents received the invitation to participate nor that they actually visited YHC at the child aged 2 years. Furthermore, the parents with a younger child, a Dutch ethnic background, an older age and a higher education level were more likely to participate in the follow-up of the study. Consequently, the findings are applicable to the population under study. Regardless, efforts should be made to involve hard-toreach populations in research studies. Finally, a lack of repeated measurements did not allow us to establish the causal association in the current study.

\section{CONCLUSION}

The predisposing, enabling and needs factors correlated with help-seeking by parents of preschool children with regards to their child's socioemotional development were evaluated. The factors of non-western ethnic background, younger age of the parent, previous help-seeking and specific discussions about the child's socioemotional development during the well-child visit were associated with the presence of parental help-seeking. Parents reported using informal help sources more often than formal help sources. The findings can be used to further develop support for parents to access adequate information, prevention and anticipatory care with regards to their child's socio-emotional development. 
Twitter Hein Raat @heinraat and Guannan Bai @Guannan Bai

Contributors HR obtained the funding and he is responsible for the overall content as the guarantor. $\mathrm{HR}, \mathrm{AG}$ and $\mathrm{RB}$ managed the research and undertook data collection. CBF, JL, AG and HR conceived the research described in this paper. JL analysed the data. All authors provided input in interpreting the data. JL drafted the manuscript with input of AG, CBF, HR and GB. All authors critically reviewed and approved the manuscript.

Funding This work was supported by ZonMw, grant number 729301001. Jie Luo was funded by the Chinese Government Scholarship (CN), grant number 201806170061.

Competing interests None declared.

Patient consent for publication Not applicable.

Ethics approval This study involves human participants and was approved by The Medical Ethical Committee of the Erasmus Medical Center Rotterdam declared that the Medical Research Involving Human Subject Act (Dutch abbreviation WMO) did not apply to the present study and, subsequently, permission was given to carry out the study and to publish the results in scientific journals (number MEC-2014-152). Participants gave informed consent to participate in the study before taking part.

Provenance and peer review Not commissioned; externally peer reviewed.

Data availability statement № data are available.

Supplemental material This content has been supplied by the author(s). It has not been vetted by BMJ Publishing Group Limited (BMJ) and may not have been peer-reviewed. Any opinions or recommendations discussed are solely those of the author(s) and are not endorsed by BMJ. BMJ disclaims all liability and responsibility arising from any reliance placed on the content. Where the content includes any translated material, BMJ does not warrant the accuracy and reliability of the translations (including but not limited to local regulations, clinical guidelines, terminology, drug names and drug dosages), and is not responsible for any error and/or omissions arising from translation and adaptation or otherwise.

Open access This is an open access article distributed in accordance with the Creative Commons Attribution Non Commercial (CC BY-NC 4.0) license, which permits others to distribute, remix, adapt, build upon this work non-commercially, and license their derivative works on different terms, provided the original work is properly cited, appropriate credit is given, any changes made indicated, and the use is non-commercial. See: http://creativecommons.org/licenses/by-nc/4.0/.

\section{ORCID iDs}

Jie Luo http://orcid.org/0000-0002-0500-0101

Hein Raat http://orcid.org/0000-0002-6000-7445

Guannan Bai http://orcid.org/0000-0003-0619-7580

Amy van Grieken http://orcid.org/0000-0001-6767-9159

\section{REFERENCES}

1 Egger HL, Angold A. Common emotional and behavioral disorders in preschool children: presentation, nosology, and epidemiology. $J$ Child Psychol Psychiatry 2006;47:313-37.

2 Kieling $\mathrm{C}$, Baker-Henningham $\mathrm{H}$, Belfer $\mathrm{M}$, et al. Child and adolescent mental health worldwide: evidence for action. Lancet 2011;378:1515-25.

$3 \mathrm{Kv}$ K, Döhnert M, Kroll M. Mental disorders in early childhood. Dtsch Arztebl International 2015;112:375-86.

4 Kariuki SM, Abubakar A, Kombe M, et al. Burden, risk factors, and comorbidities of behavioural and emotional problems in Kenyan children: a population-based study. Lancet Psychiatry 2017;4:136-45.

5 Vitrikas K, Savard D, Bucaj M. Developmental delay: when and how to screen. Am Fam Physician 2017;96:36-43.

6 Wichstrøm L, Berg-Nielsen TS, Angold A, et al. Prevalence of psychiatric disorders in preschoolers. J Child Psychol Psychiatry 2012;53:695-705.

7 Skovgaard AM. Mental health problems and psychopathology in infancy and early childhood. An epidemiological study. Dan Med Bull 2010;57:B4193.

8 Anselmi L, Piccinini CA, Barros FC, et al. Psychosocial determinants of behaviour problems in Brazilian preschool children. J Child Psychol Psychiatry 2004;45:779-88.

9 Hemmi MH, Wolke D, Schneider S. Associations between problems with crying, sleeping and/or feeding in infancy and long-term behavioural outcomes in childhood: a meta-analysis. Arch Dis Child 2011;96:622.

10 Holtmann M, Buchmann AF, Esser G, et al. The child behavior Checklist-Dysregulation profile predicts substance use, suicidality, and functional impairment: a longitudinal analysis. J Child Psychol Psychiatry 2011;52:139-47.

11 O'Connor C, Reulbach U, Gavin B, et al. A prospective longitudinal investigation of the (dis)continuity of mental health difficulties between mid- to late-childhood and the predictive role of familial factors. Eur Child Adolesc Psychiatry 2018;27:289-300.

12 Harrison JR, Vannest KJ, Reynolds CR. Social acceptability of five screening instruments for social, emotional, and behavioral challenges. Behavioral Disorders 2013;38:171-89.

13 Malik F, Marwaha R. Developmental stages of social emotional development in children. Statpearls. Treasure Island (FL): StatPearls, 2018.

14 Letcher P, Smart D, Sanson A, et al. Psychosocial precursors and correlates of differing internalizing trajectories from 3 to 15 years ${ }^{1}$. Soc Dev 2009;18:618-46.

15 Shaw DS, Lacourse E, Nagin DS. Developmental trajectories of conduct problems and hyperactivity from ages 2 to 10 . J Child Psychol Psychiatry 2005;46:931-42.

16 Patel V, Kieling C, Maulik PK, et al. Improving access to care for children with mental disorders: a global perspective. Arch Dis Child 2013;98:323-7.

17 Johnston OG, Burke JD. Parental problem recognition and helpseeking for disruptive behavior disorders. J Behav Health Serv Res 2020;47:146-63.

18 Thompson RA. Emotional regulation and emotional development. Educ Psychol Rev 1991;3:269-307.

19 Andersen RM. Revisiting the behavioral model and access to medical care: does it matter? J Health Soc Behav 1995;36:1-10.

20 Thurston IB, Hardin R, Decker K, et al. Black and white parents willingness to seek help for children's internalizing and Externalizing symptoms. J Clin Psychol 2018;74:161-77.

21 Zwaanswijk M, Verhaak PFM, Bensing JM, et al. Help seeking for emotional and behavioural problems in children and adolescents: a review of recent literature. Eur Child Adolesc Psychiatry 2003;12:153-61.

22 Morawska A, Sultan A. Parental attitudes towards seeking professional help for their children: a community sample from the Sultanate of Oman. J Child Fam Stud 2016;25:979-87.

23 Alonso J, Little E. Parent help-seeking behaviour: examining the impact of parent beliefs on professional help-seeking for child emotional and behavioural difficulties. The Educational and Developmental Psychologist 2019;36:60-7.

24 Reardon T, Harvey K, Creswell C. Seeking and accessing professional support for child anxiety in a community sample. Eur Child Adolesc Psychiatry 2020;29:649-64.

25 Girio-Herrera E, Owens JS, Langberg JM. Perceived barriers to help-seeking among parents of at-risk kindergarteners in rural communities. J Clin Child Adolesc Psychol 2013;42:68-77.

26 Iskra W, Deane FP, Wahlin T, et al. Parental perceptions of barriers to mental health services for young people. Early Interv Psychiatry 2018;12:125-34.

27 Dempster R, Davis DW, Faye Jones V, Jones VF, et al. The role of stigma in parental help-seeking for perceived child behavior problems in urban, low-income African American parents. J Clin Psychol Med Settings 2015;22:265-78.

28 Oh E, Bayer JK. Parents' help-seeking processes for early childhood mental health problems. Child Adolesc Ment Health 2015;20:149-54.

29 Beyer T, Postert C, Müller JM, et al. Prognosis and continuity of child mental health problems from preschool to primary school: results of a four-year longitudinal study. Child Psychiatry Hum Dev 2012;43:533-43.

30 Verhulst FC, van der Ende J. Factors associated with child mental health service use in the community. J Am Acad Child Adolesc Psychiatry 1997;36:901-9.

31 Oudhof M, de Wolff MS, de Ruiter M. Jgz richtlijn opvoedingsondersteuning voor hulp bij opvoedingsvragen en lichte opvoedproblemen. Utrecht, the Netherlands: Nederland Centrum Jeugdgezondheid (NCJ), 2013.

32 . Annual report on integration 2018. The Hague, the Netherlands: Statistics Netherlands; 2018.

33 Statistics Netherlands. Standaard onderwijsindeling 2016. Den Haag, the Netherlands, 2018.

34 Briggs-Gowan MJ, Carter AS. Social-emotional screening status in early childhood predicts elementary school outcomes. Pediatrics 2008;121:957-62.

35 Kruizinga I, Jansen W, De Haan CL. Reliability and validity of the Dutch version of the bitsea. PLoS One 2012;7:e38762. 
36 Briggs-Gowan MJ, Carter AS, Irwin JR, et al. The brief InfantToddler social and emotional assessment: screening for socialemotional problems and delays in competence. J Pediatr Psychol 2004:29:143-55.

37 Kruizinga I, Jansen W, De Haan CL. Reliability and validity of the Dutch version of the bitsea 2012;7.

38 Landgraf JM, Vogel I, Oostenbrink R, et al. Parent-reported health outcomes in infants/toddlers: measurement properties and clinical validity of the ITQOL-SF47. Qual Life Res 2013;22:635-46.

39 Raat $\mathrm{H}$, Landgraf JM, Oostenbrink R. Reliability and validity of the infant and toddler quality of life questionnaire (itqol) in a general population and respiratory disease sample. Qual Life Res 2007;16:445-60.

40 Raat $\mathrm{H}$, Landgraf JM, Oostenbrink R, et al. Reliability and validity of the infant and toddler quality of life questionnaire (ITQOL) in a general population and respiratory disease sample. Qual Life Res 2007:16:445-60.

41 Maroof DA. Binary logistic regression. In: Maroof DA, ed. Statistical methods in neuropsychology: common procedures made comprehensible. Boston, MA: Springer US, 2012: 67-75.

42 Liu Y, De A. Multiple imputation by fully conditional specification for dealing with missing data in a large epidemiologic study. Int J Stat Med Res 2015;4:287.

43 Andersen R, Newman JF. Societal and individual determinants of medical care utilization in the United States. Milbank Mem Fund Q Health Soc 1973;51:95-124.

44 Bussing R, Zima BT, Gary FA, et al. Barriers to detection, helpseeking, and service use for children with ADHD symptoms. J Behav Health Serv Res 2003;30:176-89.

45 Alegría M, Canino G, Lai S, et al. Understanding caregivers' helpseeking for Latino children's mental health care use. Med Care 2004;42:447-55.

46 Verhulp EE, Stevens GWJM, van de Schoot R, et al. Understanding ethnic differences in mental health service use for adolescents internalizing problems: the role of emotional problem identification. Eur Child Adolesc Psychiatry 2013;22:413-21.

47 Reardon T, Harvey K, Baranowska M, et al. What do parents perceive are the barriers and facilitators to accessing psychological treatment for mental health problems in children and adolescents? A systematic review of qualitative and quantitative studies. Eur Child Adolesc Psychiatry 2017;26:623-47.

48 Zwaanswijk M, van der Ende J, Verhaak PFM, et al. Help-Seeking for child psychopathology: pathways to informal and professional services in the Netherlands. J Am Acad Child Adolesc Psychiatry 2005;44:1292-300.

49 Shanley DC, Reid GJ, Evans B. How parents seek help for children with mental health problems. Adm Policy Ment Health 2008;35:135-46.

50 Giallo R, Dunning M, Gent A. Attitudinal barriers to help-seeking and preferences for mental health support among Australian fathers. $J$ Reprod Infant Psychol 2017;35:236-47.

51 Zimmerman FJ. Social and economic determinants of disparities in professional help-seeking for child mental health problems: evidence from a national sample. Health Serv Res 2005;40:1514-33.

52 Kroneman M, Boerma W, van den Berg M, et al. Netherlands: health system review. Health Syst Transit 2016;18:1-240.
53 van Weel C, Schers $\mathrm{H}$, Timmermans A. Health care in the Netherlands. J Am Board Fam Med 2012;25 Suppl 1:S12-17.

54 HPJP V. Youth health care in the netherlands: A bird's eye view. 1990: 86, 1044-7.

55 Goldfeld SR, Wright M, Oberklaid F. Parents, infants and health care: utilization of health services in the first 12 months of life. J Paediatr Child Health 2003;39:249-53.

56 Hanna BA, Edgecombe G, Jackson CA, et al. The importance of firsttime parent groups for new parents. Nurs Health Sci 2002;4:209-14.

57 Zahner GE, Daskalakis C. Factors associated with mental health, general health, and school-based service use for child psychopathology. Am J Public Health 1997;87:1440-8.

58 Sawyer MG, Miller-Lewis LR, Clark JJ. The mental health of 13-17 year-olds in Australia: findings from the National survey of mental health and well-being. J Youth Adolesc 2007;36:185-94.

59 Turner EA, Mohan S. Child mental health services and psychotherapy attitudes among Asian Indian parents: an exploratory study. Community Ment Health J 2016;52:989-97.

60 Costello EJ, Mustillo S, Erkanli A, et al. Prevalence and development of psychiatric disorders in childhood and adolescence. Arch Gen Psychiatry 2003;60:837-44

61 Alexander KE, Brijnath B, Mazza D. 'Can they really identify mental health problems at the age of three?' parent and practitioner views about screening young children's social and emotional development. Aust N Z J Psychiatry 2013;47:538-45.

62 Coker TR, Shaikh Y, Chung PJ. Parent-reported quality of preventive care for children at-risk for developmental delay. Acad Pediatr 2012:12:384-90.

63 Raviv A, Sharvit K, Raviv A. Mothers' and fathers' reluctance to seek psychological help for their children. Journal of Child and Family Studies 2009;18:151.

64 Mitchell RE, Trickett EJ. Task force report: social networks as mediators of social support. Community Ment Health $J$ 1980;16:27-44

65 Murry VM, Heflinger CA, Suiter SV, et al. Examining perceptions about mental health care and help-seeking among rural African American families of adolescents. J Youth Adolesc 2011;40:1118-31.

66 Karim N, Boyle B, Lohan M, et al. Immigrant parents' experiences of accessing child healthcare services in a host country: a qualitative thematic synthesis. J Adv Nurs 2020;76:1509-1519.

67 Achenbach TM, McConaughy SH, Howell CT. Child/adolescent behavioral and emotional problems: implications of cross-informant correlations for situational specificity. Psychol Bull 1987;101:213

68 Achenbach TM. The child behavior checklist and related instruments, 1999.

69 Coughlin SS. Recall bias in epidemiologic studies. J Clin Epidemiol 1990;43:87-91.

70 Nohr EA, Frydenberg M, Henriksen TB, et al. Does low participation in cohort studies induce bias? Epidemiology 2006;17:413-8.

71 Elemraid M, Pollard K, Thomas M, et al. Parental decisions on children participating in research. Nurs Child Young People 2013;25:16-21.

72 Levickis P, Naughton G, Gerner B, et al. Why families choose not to participate in research: feedback from non-responders. $J$ Paediatr Child Health 2013;49:57-62. 